\title{
An ERP Knowledge Transfer Framework for Strategic Decisions in Knowledge Management in Organizations
}

\author{
Uchitha Jayawickrama, Shaofeng Liu, and Melanie Hudson Smith
}

\begin{abstract}
Enterprise Resource Planning (ERP) system implementation requires wide range of knowledge from various parties and transferring the right amount of knowledge between individuals during implementation is of paramount importance. Hence, ERP knowledge transfer has been recognized as one of the most essential antecedents for a successful ERP implementation. This study defines an ERP knowledge transfer (EKT) framework for ERP implementations based on empirical findings which also considers strategic decisions to be made during implementation for effective knowledge management (KM). It classifies specific knowledge elements under ERP package knowledge and business process knowledge separately which needs to be transferred between implementation consultants and business users. In addition, key findings inform industry practitioners on how, why and with-what various types of knowledge have to be transferred during ERP project with the effects of knowledge determinants.
\end{abstract}

Index Terms-ERP knowledge transfer, enterprise resource planning, strategic decisions, knowledge management, ERP implementation.

\section{INTRODUCTION}

An Enterprise Resource Planning (ERP) system is a widely-known state-of-the-art information system which automates the business processes of an organization into a single integrated system [1], [2]. It helps users in various management levels of an organization to make sound decisions based on the integrated business information available through the system [3]. Therefore, it is able to increase organizational performance by lowering operational costs and maximizing revenue. Moreover, it enables businesses to improve customer services and supplier management. The implementation of such a complex system requires many resources like competent consultants, knowledgeable business users, sophisticated project management techniques, relevant change management strategies, etc [4]. Therefore, it is necessary to use sufficient levels of those resources through making correct strategic decisions by the company top management.

The knowledge and capability of transferring relevant knowledge between individuals have been identified as vital sources of a company's sustainable competitive advantage [5]. Strategic alliances and globalization have made effective knowledge transfer central to an organization's success. ERP implementation requires wide range of knowledge from implementation consultants and business users. The

Manuscript received April 5, 2014; revised July 7, 2014.

The authors are with the Plymouth Graduate School of Management, University of Plymouth, United Kingdom (e-mail uchitha.jayawickrama@plymouth.ac.uk). knowledge of system functionalities and knowledge of existing business processes are among the important knowledge elements for a successful ERP implementation [6], [7]. The knowledge exists at many levels in firms, and it's transferred from individual level to groups, departments and divisions. At the start of a project, implementation consultants possess ERP package related knowledge and business users have knowledge related to company business processes [8]. Effective implementation requires business users to learn ERP package knowledge from consultants and consultants to absorb business process knowledge from business users.

This paper presents an ERP knowledge transfer framework for ERP implementations based on empirical evidence which also considers strategic decisions needed to be made during implementation for effective knowledge management (KM) in organizations. The subsequent sections of this paper unfold as follows; relevant literature will be discussed in the next section, followed by the research method section. Then the empirical findings will be presented under four sub-sections. Before concluding, a further discussion of the ERP knowledge transfer framework will be presented. Finally, management implications, limitations and further research are considered in the Conclusions section.

\section{RELATED WORK}

ERP systems related research studies have been mostly carried out around ERP implementation success factors, failure factors, selection of ERP packages and critical factors [9]-[14]. There are only a small number of studies that specifically concentrate on issues relating to the management of knowledge during ERP implementation. Hence, this section explores the relevance of those studies that assisted to formulate this research study by identifying the knowledge gap.

Chen [15] divides empirical knowledge into four different layers: "know-what", "know-why", "know-how", and "know-with" in the conceptual model based on the empirical knowledge characterization. He uses these four knowledge layers for his study conducted to IT sector in general. Even though it has knowledge layers (k-layers) involved, there has not been a context of knowledge transfer and knowledge types (k-types) related to ERP implementations.

A study carried out by [8], revealed four sets of factors (characteristics of knowledge to be transferred, source, recipient and context) which have different effects on ERP knowledge transfer from implementation consultants to key users and vice versa. Maditinos, Chatzoudes and Tsairidis [16] present a conceptual framework that investigates the 
way that human inputs are linked to communication effectiveness, conflict resolution and knowledge transfer. They also show the effect of these factors on successful ERP implementation. Moreover, they find that knowledge transfer is positively related to user support and consultant support. They also discover the importance of correct strategic decisions taken by the top management in order to resolve conflicts and improve communication between users and consultants for effective ERP knowledge transfer. In a study, [17] identifies two major areas of concern regarding the management of knowledge in ERP projects through the developed framework: managing tacit knowledge and issues concerning the process-based nature of organizational knowledge. Also, he identifies that facilitators are able to moderate these negative effects. Jones, Cline and Ryan [18] examined eight dimensions of culture and their impact on how the ERP implementation team is able to effectively share knowledge during implementation. This study shows ways to overcome cultural barriers to knowledge sharing. Furthermore, it develops a model that demonstrates the link between the dimensions of culture, and knowledge sharing during ERP implementation. However, these studies lack the integration of different knowledge dimensions such as k-layers, k-types and k-determinants.

Alavi and Leidner [19] identified four knowledge types such as organization culture, business framework, ERP package and project, and this can be seen as the only study which considered most number of knowledge types in one study in order to broadly understand the issues of knowledge management in ERP implementations. Liu [20] discovers the influence of critical success factors on ERP knowledge management, but this study only examines one k-type which is ERP knowledge. Moreover, [21] examines the use of KM to support ERP systems across the entire lifecycle, with particular interest in case-based KM. However, these studies lack the dimension of knowledge layers as to reveal how, why, and with-what the different types of knowledge have been transferred during the implementation.

It is common that the past studies discussed in this section have explored knowledge types, knowledge layers and knowledge transfer in isolation. None of the studies have been able to explore the integrated effect of k-types, k-layers and knowledge transfer for ERP implementation. There has been a significant shortage of empirical research on knowledge transfer during ERP implementation; even effective knowledge transfer has been identified as a major aspect for ERP project success [22]. Hence, it demands the necessity of conducting more research on ERP knowledge transfer.

\section{RESEARCH METHOD}

This section discusses the empirical data collection and data analysis methods adopted in this study. One-to-one semi-structured interviews have been selected as the main data collection technique over other methods such as focus groups, Delphi method, questionnaires, etc. This study tries to discover why, how and with-what the relevant knowledge types have been transferred between various parties during ERP implementation [23], [24]. This requires in-depth dialogues with ERP experts in order to identify what has happened in-detail with respect to knowledge management aspects in separate projects [25], [26]. The interviews were carried out with ERP experts on 14 different ERP implementations in the UK and each interview lasted for 2 hours on average. The experts largely hold senior management positions (such as managing director, head of IT, business systems manager, head of business solutions, project lead, principal consultant, project manager, etc.) in client and vendor companies and this helped to obtain details of what happened during the whole project with the big picture. They all had direct work experience in ERP implementations for more than 10 years which indicates a high level of skills, in-depth knowledge and experience in the field of ERP. Company case implementations were investigated with three different sources of evidence: in-depth one-to-one interviews, analysis of ERP project related documents, and validation of coded data with the respective companies. Various UK manufacturing and service sector companies are among the 14 case implementations and those companies have implemented SAP and Oracle ERP systems. The interviews were carried out until the data saturation point was reached.

This study has used three qualitative data analysis techniques in order to analyze word-for-word interview transcripts and ERP project related documents, they are: thematic analysis, comparative analysis and content analysis [27]-[29]. The thematic analysis helps to identify new emerging themes from the data collected [28]. Thereby, different components of the framework and inter-relationships between them have been discovered by the emerging themes from the coded data. The comparative analysis is closely connected with thematic analysis, the difference is that it allows to compare and contrast data collected by different sources [28], [29]. These comparisons continue until the point where new themes stop emerging. Thereby, this study compares and contrasts data obtained from 14 case implementations in order to confirm empirical findings across implementations. Moreover, this analysis technique has helped to find out the data saturation point and thereby stop carrying out further interviews. The process is much more mechanical in content analysis with the analysis being left until the data has been collected [27], [29]. It allows to systematically work through each transcript/ERP project document to assign codes. The codes have been assigned using NVivo software in order to count and confirm the frequency of occurrence of components in the framework, for example, confirmation on the applicability of knowledge determinants. Furthermore, the software has been used to organize and structure all data collected for this study.

\section{EMPIRICAL FINDINGS}

The ERP knowledge transfer (EKT) framework has been modelled by summarizing the empirical findings of this study and the framework can be seen in Fig. 1. There are three knowledge components which enhance knowledge transfer activities during ERP implementations, they are: k-layers, k-types and k-determinants. The k-layers are comprised of know-what, know-how, know-why and know-with as shown in the first level of the framework. The second level denotes two k-types i.e. ERP package knowledge and business 
process knowledge that have been largely important for a successful implementation. The last and the third layer comprises of five k-determinants which affect the transfer of two knowledge types. The organization structure is the only k-determinant applicable only to ERP package knowledge as shown in the EKT framework. All other determinants are supporting to transfer both ERP package and business process knowledge during ERP implementations. Out of the four knowledge types discussed in the literature, only two have been formally managed during implementations i.e. ERP package knowledge and business process knowledge. The organizational cultural and project management knowledge have not been formally managed through the use of KM lifecycle phases [30].

The empirical findings will be discussed under four k-layers in order to easily understand the integration of knowledge transfer with various knowledge components and elements in the EKT framework. Moreover, Table I provides an overall picture of the ideas that will be discussed under the four sub-topics below.

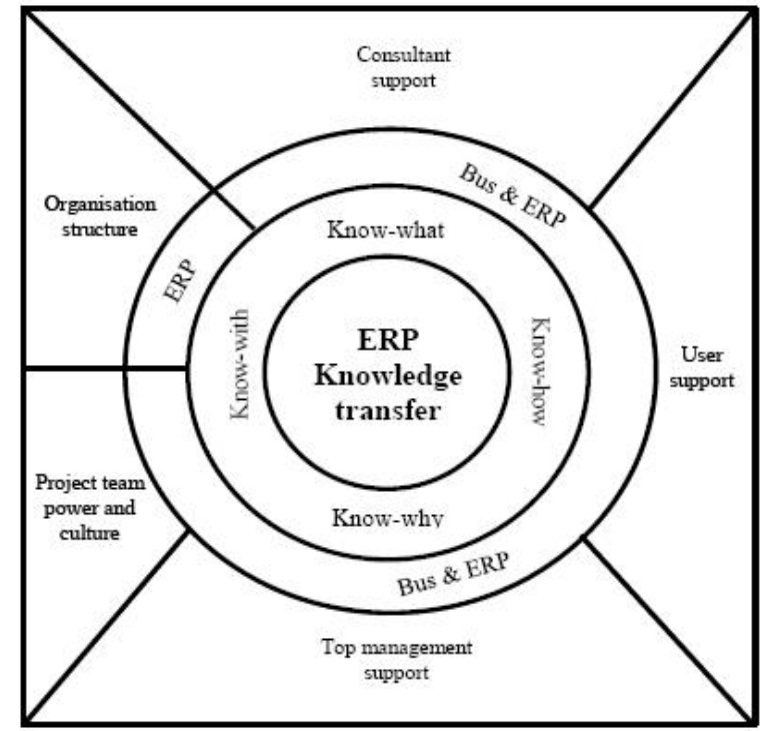

Fig. 1. ERP knowledge transfer (EKT) framework.

TABLE I: SPECIFICS ON KNOWLEDGE TRANSFER INTEGRATION

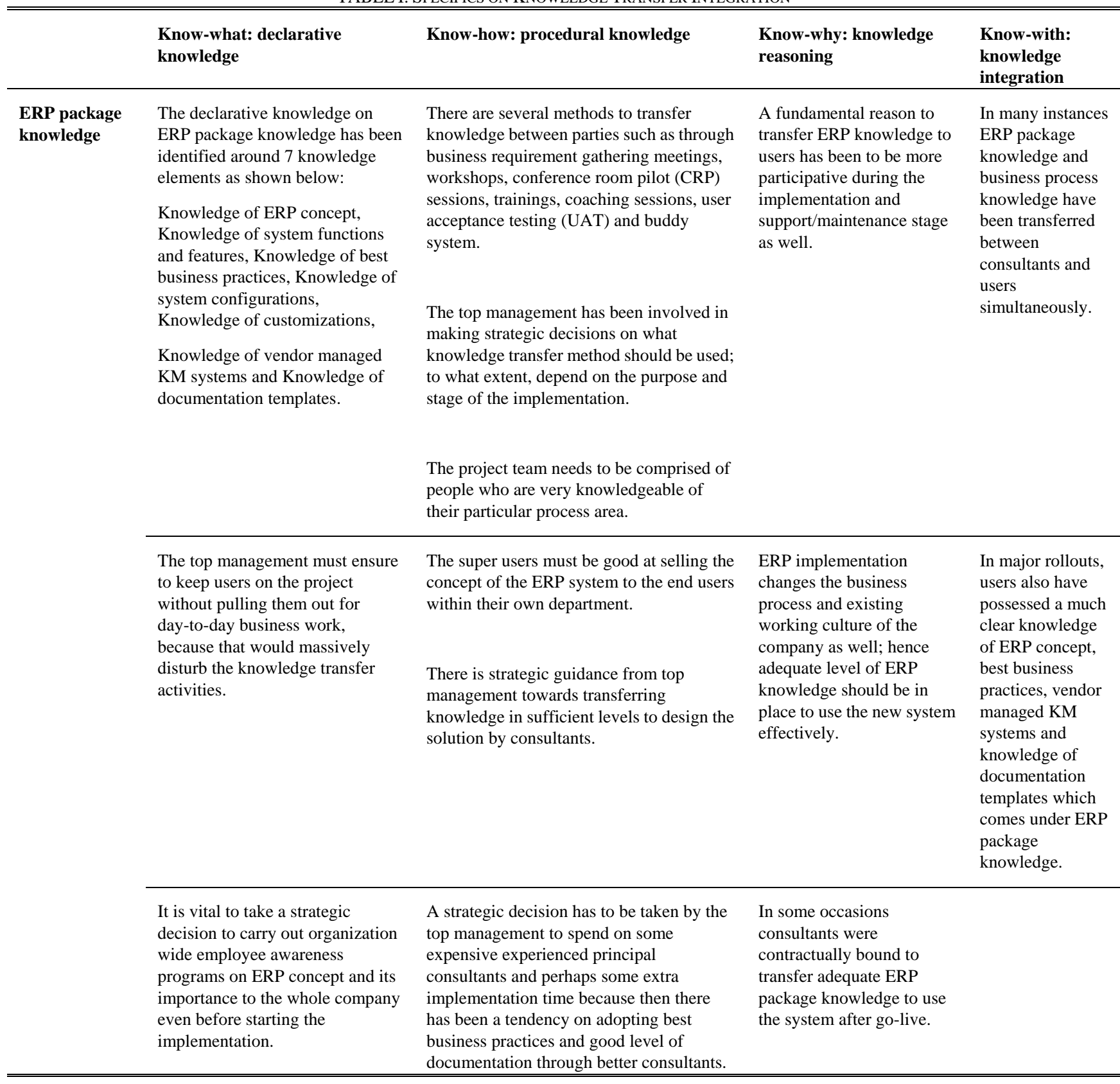




\begin{tabular}{|c|c|c|c|c|}
\hline & $\begin{array}{l}\text { The top management has to take } \\
\text { strategic decisions on determining } \\
\text { on the customization points and } \\
\text { incorporating best business } \\
\text { practices based on the ERP } \\
\text { package knowledge that they } \\
\text { possess. }\end{array}$ & $\begin{array}{l}\text { The consultants have been sitting side by } \\
\text { side with business users to ensure smooth } \\
\text { knowledge transfer between both parties. } \\
\text { The importance to come up with the } \\
\text { organization structure after the } \\
\text { implementation and start transferring } \\
\text { relevant ERP package knowledge to the } \\
\text { respective individuals in right quantities } \\
\text { from the beginning of the project. }\end{array}$ & $\begin{array}{l}\text { The level of the ERP } \\
\text { package knowledge } \\
\text { required (particularly } \\
\text { knowledge of system } \\
\text { configurations) is } \\
\text { important to take a strategic } \\
\text { decision on whether the } \\
\text { client company is hoping to } \\
\text { build up its own internal } \\
\text { team to carry out future } \\
\text { ERP rollouts or not. }\end{array}$ & \\
\hline \multirow[t]{4}{*}{$\begin{array}{l}\text { Business } \\
\text { process } \\
\text { knowledge }\end{array}$} & $\begin{array}{l}\text { The declarative knowledge on } \\
\text { business process knowledge has } \\
\text { been identified around } 7 \\
\text { knowledge elements as shown } \\
\text { below: } \\
\text { Knowledge of current business } \\
\text { processes, Knowledge of client's } \\
\text { industry, Knowledge of business } \\
\text { requirements, }\end{array}$ & $\begin{array}{l}\text { It is vital to build up a good relationship } \\
\text { between users and consultants by letting } \\
\text { users know why consultants want the } \\
\text { business information and how it will be } \\
\text { used for the implementation. }\end{array}$ & $\begin{array}{l}\text { The knowledge of current } \\
\text { business processes has been } \\
\text { vital to improve the } \\
\text { processes which would get } \\
\text { after the implementation } \\
\text { and it has also helped to } \\
\text { understand how one's work } \\
\text { relates to others tasks. }\end{array}$ & $\begin{array}{l}\text { In major rollouts, } \\
\text { it has been easier } \\
\text { for consultants to } \\
\text { understand } \\
\text { business } \\
\text { requirements, } \\
\text { current business } \\
\text { processes and } \\
\text { industry practices } \\
\text { of the client } \\
\text { company. }\end{array}$ \\
\hline & $\begin{array}{l}\text { Knowledge of current systems } \\
\text { landscape (if any), Knowledge of } \\
\text { As Is document templates, } \\
\text { Knowledge of existing modules } \\
\text { implemented (if any) and } \\
\text { Knowledge of company big } \\
\text { picture. }\end{array}$ & $\begin{array}{l}\text { The business requirement gathering } \\
\text { meetings and process workshops have been } \\
\text { widely used to transfer business process } \\
\text { knowledge from users to consultants. }\end{array}$ & $\begin{array}{l}\text { As Is process documents } \\
\text { have been benefited not } \\
\text { only to consultants but also } \\
\text { client side employees in } \\
\text { different management } \\
\text { levels including senior } \\
\text { executives to understand } \\
\text { the business completely. }\end{array}$ & \\
\hline & $\begin{array}{l}\text { The consultant's vast experience } \\
\text { on previous implementations done } \\
\text { in client's industry sector will } \\
\text { solve the problem of addressing } \\
\text { industry specific process issues } \\
\text { which would be in the list of } \\
\text { business requirements. }\end{array}$ & & & \\
\hline & $\begin{array}{l}\text { In the case of a major rollout, } \\
\text { consultants have been able to } \\
\text { easily understand the interaction } \\
\text { of existing modules implemented. }\end{array}$ & & & \\
\hline
\end{tabular}

\section{A. Know-What: Declarative Knowledge}

The know-what k-layer has been used to discover facts about problems and solutions in ERP knowledge transfer with respect to ERP package knowledge and business process knowledge. The declarative knowledge on ERP package knowledge has been identified around 7 knowledge elements, they are: knowledge of ERP concept, system functions and features, best business practices, system configurations, customizations, vendor managed KM systems and knowledge of documentation templates. When transferring the knowledge of system functions and features to the client project team members, there was a concern according to the empirical findings, i.e. the knowledge absorption capacity of the recipient [8]. The project team members should be carefully selected by considering their working capacity and competence on information technology through conducting internal interviews. A functional consultant describes the ability of project team members as: "The end users the people who were nominated for the project team, the project team members and those that participated in the design blueprint, were very willing and able and very knowledgeable in their particular processes..." Not only that, but also top management must ensure to keep users on the project without pulling them out, because that would massively disturb the knowledge transfer activities. Therefore, it's a must to plan and schedule their work in advance for them to involve in project work, if required in their day-to-day business work. The lack of the ERP big picture was discovered as a problematic area in ERP knowledge transfer. Whoever is involved in the project activities has to have a concrete idea about the ERP concept initially, but not its details. Therefore, it is vital to take a strategic decision to carry out organization wide employee awareness programs (kick-off workshops, monthly bulletin, newsletters, etc.) on the ERP concept and its importance to the whole company even before starting the implementation. The management of customizations and the extent of incorporating best business practices are two main knowledge issues that have been recognized based on the empirical evidence from case implementations. The top management has to take strategic decisions on determining on the customization points and incorporating best business practices based on the ERP package knowledge that they possess. Therefore, implementation partner should table out the options of customizations vs. adoption of best business practices with the pros and cons of each option for the client's top management to decide on the same. The knowledge of system configurations, vendor managed KM systems and documentation templates have largely been transferred after the business requirement gathering stage, because at that time the users have a great deal of understanding of the ERP concept and system functionalities in order to digest additional knowledge.

There are $7 \mathrm{k}$-elements with respect to the declarative 
knowledge on business process knowledge, they are: knowledge of current business processes, client's industry, business requirements, current systems landscape (if any), As Is document templates, existing modules implemented (if any) and knowledge of company big picture. The consultant's vast experience on previous implementations done in client's industry sector will solve the problem of addressing industry specific process issues which would be in the list of business requirements. As per the findings, users were not willing to transfer the knowledge of current business processes to consultants due to fear of losing their job after the implementation. Awareness campaigns and monthly bulletins even before formally starting the implementation would help users to get to know the purpose of the ERP system implementation and how it impacts to advance their careers. It is vital to transfer the knowledge of current systems landscape from users to consultants if legacy systems are in-place to automate any business activities. An implementation of different modules in the same ERP as a separate project is known as ERP rollout. In the case of a major rollout, consultants have been able to easily understand the interaction of existing modules implemented based on the empirical evidence, mainly because they have the knowledge of the modules in the same ERP product.

\section{B. Know-How: Procedural Knowledge}

This section explains how to transfer knowledge from users to consultant and vice versa. The business process knowledge has largely been transferred from users to consultants, whereas ERP package knowledge has largely been transferred from consultants to users. The study reveals several methods to transfer knowledge between parties such as through business requirement gathering meetings, workshops, conference room pilot (CRP) sessions, trainings, coaching sessions, user acceptance testing (UAT) and buddy system. There are various types of project workshops depending on the purpose such as kick-off workshops (at the very start of the project, to familiarize with each other from client and vendor sides through team building activities), process workshops (to go through current business processes with users and provide consultants ideas on the same) and cross team workshops (to discuss points where two or more modules interact with each other and how it affects the users in different departments). In the same way, training is also in different modes such as generic and comprehensive, class room training and computer aided web training. The findings confirmed that coaching sessions are one-to-one discussions conducted with very small groups in order to teach complex and critical functionalities of the system. After configuring the system, the consultants take users through the ERP system functionalities in CRP sessions. UAT is done after the training sessions, there the users follow the UAT scripts and confirm whether the system functionalities meet business requirements. The top management has been involved in making strategic decisions on what knowledge transfer method should be used; to what extent, depend on the purpose and stage of the implementation.

The project power and culture determines the knowledge transfer of both ERP package and business process knowledge as per findings of this study (see Fig. 1). The project team needs to be comprised of people who are very knowledgeable of their particular process area. The key element is that they need to be empowered and they need to be able to make ERP project related decisions without going through many levels of management. The super users must be good at selling the concept of the ERP system to the end users within their own department. There is strategic guidance from top management towards transferring knowledge in sufficient levels to design the solution by consultants, since the top management has a desire to change the process to make it more standard according to the majority of case implementations. However, only 5 out of 14 cases mentioned that the top management has given only general guidance on the project, but not specific guidance on knowledge transfer. A strategic decision has to be taken by the top management to spend on some expensive experienced principal consultants and perhaps some extra implementation time because then there has been a tendency on adopting best business practices and good level of documentation through better consultants. Moreover, they may have to decide on recruiting internal staff with relevant skill sets and experience to bridge the compulsory knowledge gaps. Most of the users have considered this opportunity to enhance their CVs by working with a famous standard ERP system implementation. Therefore, they have been very supportive and positive towards project activities based on the findings. Some of the occasions, users have demanded the relevant ERP package knowledge from the consultants to perform their jobs smoothly within the new system. On the other hand, for the users who are not positive towards the new implementation, it is vital to build up a good relationship between users and consultants by letting users know why consultants want the business information and how it will be used for the implementation. The consultant support is another k-determinant for ERP package and business process knowledge transfer (see Fig. 1). The study found that consultants have been sitting side by side with business users to ensure smooth knowledge transfer between both parties. Furthermore, the study also reveals that a better way of two-way knowledge transfer is looking at how the business process fit into the ERP package rather than just going through the existing business processes. The consultant support also demonstrated by maintaining sufficient number of consultants in the implementation at a given time depending on the stage of the implementation by the implementation partner. A principal consultant states that "Knowledge has no value unless it's with the right people and then when you look at now who needs to have that knowledge over the lifecycle of a project..." Thereby, the research discovers the importance to come up with the organization structure after the implementation and start transferring relevant ERP package knowledge to the respective individuals in right quantities from the beginning of the project. Otherwise, a particular job position would no longer be there when the new system is in place, instead a different position would be created without proper knowledge to use and maintain the new system. Overall this section explained numerous methods on transferring relevant knowledge between users and consultants with the support of five k-determinants.

\section{Know-Why: Knowledge Reasoning}

This k-layer helps to identify principles underlining ERP knowledge transfer of know-what and know-how. This 
section combines various aspects discussed under know-what and know-how in order to explain why ERP package knowledge and business process knowledge have been transferred between parties during the implementation. The knowledge of current business processes has been vital to improve the processes which would get after the implementation and it has also helped to understand how one's work relates to others' tasks based on the empirical evidence. The final outcome of the business requirement gathering stage has been As Is process documents after carrying out various knowledge transfer activities. And these documents have been benefited not only to consultants but also client side employees in different management levels including senior executives to understand the business completely.

A fundamental reason to transfer ERP knowledge to users has been to be more participative during the implementation and support/maintenance stage as well. Then users see the whole system end-to-end and users become comfortable and effective when they start to use the system after go-live. One project manager states that 'It's not like a security system where the only business interaction is when you swipe the card. So that is a real technical implementation. With an ERP you are into business process and you are into culture change where it is to standardization." Therefore, it's evident that the ERP implementation changes the business process and existing working culture of the company as well; hence adequate levels of knowledge should be in place to use the new system effectively. Moreover, on some occasions the knowledge transfer was signed off as one of the requirements in the ERP project agreement; therefore consultants were legally bound to transfer adequate ERP package knowledge to use the system after go-live. Lastly, the level of the ERP package knowledge required (particularly the knowledge of system configurations) is important to take a strategic decision on whether the client company is hoping to build up its own internal team to carry out future ERP rollouts or not.

\section{Know-with: Knowledge Integration}

This section describes the inter-relationships between knowledge types (ERP package and business process knowledge) and knowledge elements under each knowledge type. The empirical findings reveal that in many instances ERP package knowledge and business process knowledge have been transferred between consultants and users simultaneously. For example, users and consultants have looked at how the business process fits into the ERP package rather than just gathering knowledge on business processes or carrying out trainings alone. A managing director emphasizes on simultaneous knowledge transfer as "...coupling a super user with a consultant right at the start of the project and making sure that they are working together."

When it comes to a major rollout of a client company, then the knowledge of existing modules implemented has been greatly within the knowledge of system functions and features possessed by consultants. In such a situation, users have also possessed a much clear knowledge of ERP concept, best business practices, vendor managed KM systems and knowledge of documentation templates which comes under ERP package knowledge. On the other hand, it has been easier for consultants to understand business requirements, current business processes and industry practices of the client company. In summary, it is evident from the findings that most of the inter-relationships between k-elements under both k-types have existed in major rollout situations except for a few instances.

Overall, the findings of this study have shown in-detail how, why and with-what the ERP package knowledge and business process knowledge have been transferred during ERP implementation by taking important strategic decisions into consideration for effective knowledge management.

\section{DISCUSSION}

The ERP package knowledge and business process knowledge have been discovered as two significant k-types which need to be transferred during ERP implementations. This study also reveals $7 \mathrm{k}$-elements under each k-type based on the empirical evidence. Moreover, there are four k-determinants (project team power and culture, top management support, user support and consultant support) which drive knowledge transfer activities for both ERP package knowledge and business process knowledge. The k-determinant of organization structure drives knowledge transfer activities for ERP package knowledge only (see Fig. 1). In addition, ERP knowledge transfer (EKT) framework has identified declarative knowledge, procedural knowledge, reasons for knowledge transfer and integrative knowledge separately with the use of k-layers i.e. know-what, know-how, know-why and know-with. This detailed knowledge can be used by practitioners who are involving in ERP implementations.

$\mathrm{Xu}$ and $\mathrm{Ma}$ [8] explored the knowledge transfer between key users and implementation consultants and vice versa. However, it was not able to discover the detailed knowledge that needs to be transferred, how and why it has to be transferred during ERP implementation, whereas this study has been able to discover specific detailed knowledge which required for ERP knowledge transfer with the use of k-layers. Chen [15] investigates the effects of four knowledge layers for IT industry and through this study k-layers were used specifically to ERP knowledge transfer context integrated with k-types and k-determinants. Furthermore, this study shows the strategic decisions required to be made for effective ERP knowledge transfer during ERP projects (see Table I).

This research has discovered the effects of integration of three knowledge components based on empirical findings of 14 case implementations. Also, the study demonstrates how EKT framework reflects and consolidates the real industry situations in order to effectively transfer knowledge in future ERP implementations.

\section{CONCLUSIONS}

There are several key contributions applicable to industry practitioners as well as academics. Firstly, this study has discovered the k-determinants for ERP knowledge transfer in order to ease the transferring of business process and ERP package knowledge. Secondly, it classifies k-elements under both knowledge types which have to be transferred between business users and consultants based on empirical evidence. 
Therefore, practitioners can focus on specific knowledge elements when transferring knowledge using various techniques during different stages of the project. Thirdly, it informs ERP implementers about the most important knowledge types and how, why and with-what to transfer specific detailed knowledge during an ERP implementation by considering strategic decisions for knowledge transfer in order to achieve project success. Fourthly, the ERP knowledge transfer (EKT) framework shows k-determinants that are only applicable for one k-type (organization structure for ERP package knowledge) and k-determinants applicable for both k-types. Thereby, this study adds new academic knowledge to knowledge management for ERP domain.

However, this study has some limitations, such as; the case implementations only cover SAP and Oracle ERP product implementations in UK. Also, it concentrates only on the implementation stage, not pre or post implementation stages.

Further research is being carried out to link this work to other phases of the knowledge management lifecycle which includes creation, retention and application phases. It will obtain responses from a wider audience by carrying out a questionnaire survey in order to prioritize k-types and k-elements which have been discovered in this study. Finally, the research will be extended for the pre and post implementation stages as well.

\section{REFERENCES}

[1] T. H. Davenport, "Putting the enterprise into the enterprise system," Harvard Business Review, vol. 76, no. 4, pp. 121-131, Jul.-Aug. 1998.

[2] $\mathrm{H}$. $\mathrm{Li}$ and $\mathrm{L}$. $\mathrm{Li}$, "Integrating systems concepts into manufacturing information systems," Systems Research and Behavioral Science, vol. 17, pp. 135-147, Apr. 2000.

[3] D. E. O'Leary, Enterprise Resource Planning System: Systems, Lifecycle, Electronic Commerce and Risk, Cambridge, UK, 2000.

[4] K. Kumar and J. van Hillegersberg, "Enterprise resource planning experiences and evolution," Communications of the ACM, vol. 43, no. 3 , pp. 22-26, 2000.

[5] R. Poston and S. Grabski, "Financial impacts of enterprise resource planning implementations," International Journal of Accounting Information Systems, vol. 2, no. 4, pp. 271-294, December 2001

[6] P. Murray, "Knowledge management as a sustained competitive advantage," Ivey Business Journal, vol. 66, no. 4, pp. 71-76, Mar.-Apr. 2002.

[7] D. Sedera and G. Gable, "Knowledge management competence for enterprise system success," Journal of Strategic Information Systems, vol. 19, pp. 296-306, December 2010.

[8] Q. Xu and Q. Ma, "Determinants of ERP implementation knowledge transfer," Information \& Management, vol. 45, no. 8, pp. 528-539, October 2008.

[9] F. Nah, J. Lau, and J. Kuang, "Critical factors for successful implementation of enterprise systems," Business Process Management Journal, vol. 7, no. 3, pp. 285-296, 2001.

[10] T. M. Somers and K. Nelson, "The impact of critical success factors across the stages of enterprise resource planning implementations,' presented at the 34th Hawaii International Conference on System Sciences (HICSS), Maui, Hawaii, 2001.

[11] K.-K. Hong and Y.-G. Kim, "The critical success factors for ERP implementation: an organizational fit perspective," Information \& Management, vol. 40, no. 1, pp. 25-40, October 2002.

[12] A. Wong, H. Scarbrough, P. Chau, and R. Davison, "Critical failure factors in ERP implementation," presented at the ninth Pacific Asia Conference on Information Systems (PACIS), Bangkok, Thailand, 2005.

[13] W.-H. Tsai, P.-L. Lee, Y.-S. Shen, and H.-L. Lin, "A comprehensive study of the relationship between enterprise resource planning selection criteria and enterprise resource planning system success," Information \& Management, vol. 49, no. 1, pp. 36-46, January 2012.

[14] U. Jayawickrama and S. Yapa, "Factors affecting ERP implementations: Client and consultant perspectives," Journal of
Enterprise Resource Planning Studies, vol. 2013, pp. 1-13, February 2013.

[15] Y.-J. Chen, "Development of a method for ontology-based empirical knowledge representation and reasoning," Decision Support Systems, vol. 50, pp. 1-20, December 2010.

[16] D. Maditinos, D. Chatzoudes, and C. Tsairidis, "Factors affecting ERP system implementation effectiveness," Journal of Enterprise Information Management, vol. 25, no. 1, pp. 60-78, 2012.

[17] R. Vandaie, "The role of organizational knowledge management in successful ERP implementation projects," Knowledge-Based Systems, vol. 21, pp. 920-926, December 2008.

[18] M. C. Jones, M. Cline, and S. Ryan, "Exploring knowledge sharing in ERP implementation, an organizational culture framework," Decision Support Systems, vol. 41, no. 2, pp. 411-434, January 2006.

[19] M. Alavi and D. Leidner, "Review: knowledge management and knowledge management systems: conceptual foundations and research issues," MIS Quarterly (MISQ Review), vol. 25, no. 1, pp. 107-136, Mar 2001.

[20] P.-L. Liu, "Empirical study on influence of critical success factors on ERP knowledge management on management performance in high-tech industries in Taiwan," Expert Systems with Applications, vol. 38, no. 8, pp. 10696-10704, August 2011.

[21] D. E. O'Leary, "Knowledge management across the enterprise resource planning systems life cycle," International Journal of Accounting Information Systems, vol. 3, pp. 99-110, 2002.

[22] G. Gable, "The enterprise system lifecycle: through a knowledge management lens," Strategic Change, vol. 14, pp. 255-263, September 2005.

[23] P. Kraemmerand, C. Møller, and H. Boer, "ERP implementation: An integrated process of radical change and continuous learning," Production Planning \& Control, vol. 14, no. 4, pp. 338-348, June 2003.

[24] S. Liu, J. Moizer, P. Megicks, D. Kasturiratne, and U. Jayawickrama, "A knowledge chain management framework to support integrated decisions in global supply chains," Production Planning \& Control, 2013.

[25] R. Baskerville, S. Pawlowski, and E. McLean, "Enterprise resource planning and organizational knowledge: patterns of convergence and divergence," presented at the International Conference on Information Systems, 2000.

[26] R. McAdam and A. Galloway, "Enterprise resource planning and organisational innovation: a management perspective," Industrial Management \& Data Systems, vol. 105, no. 3, pp. 280-290, 2005.

[27] M. B. Miles and A. M. Huberman, An Expanded Sourcebook Qualitative Data Analysis, California, 1994.

[28] C. Dawson, Practical Research Methods, Oxford, 2002.

[29] P. Tharenou, R. Donohue, and B. Cooper, Management Research Methods, New York, 2007.

[30] U. Jayawickrama, S. Liu, and M. Hudson Smith, "An integrative knowledge management framework to support ERP implementation for improved management decision making in industry," in Lecture Notes in Business Information Processing, J. E. Hernandez, S. Liu, B. Delibasic, P. Zarate, F. Dargam, and R. Ribeiro, Ed., Springer, 2013 vol. 164 , pp. 86-101.

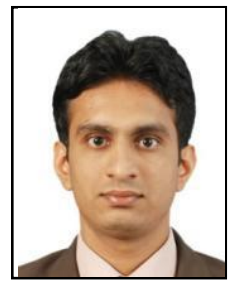

Uchitha Jayawickrama is currently a doctora researcher at Faculty of Business, University of Plymouth, United Kingdom. He worked as an Oracle applications consultant for oracle e-business suite (ERP) systems implementation in various industries $\mathrm{He}$ is an MBA holder from University of $\mathrm{Sr}$ Jayewardenepura, Sri Lanka. He obtained his BSc. honours degree in information systems from Sri Lanka Institute of Information Technology (SLIIT), Sri Lanka. His main research and teaching interests are in ERP systems, knowledge management, decision making and information systems. He has published research papers in journals and presented his research studies at different international conferences.

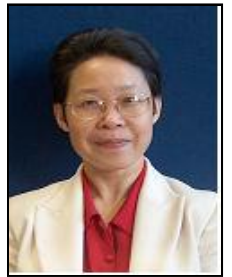

Shaofeng Liu is a professor of operations management and decision making at the University of Plymouth, UK. She obtained her PhD degree from Loughborough University, UK, specializing in knowledge and information management for global manufacturing co-ordination decisions. Her main research interests and expertise are knowledge-based techniques to support business decision making, particularly in the areas of knowledge management, integrated decision support, ERP systems and quantitative decision methods 
for lean operations, process improvement, resource management, quality management, and supply chain management. She is currently supervising 9 $\mathrm{PhD}$ students in above research areas. She has undertaken a number of influential research projects funded by UK research councils and the European Commission. She has published over 100 peer-reviewed research papers including 50 journal articles, 5 book chapters, 48 conference papers, and editorial for 6 journal Special Issues and 5 conference/workshop proceedings. She is currently an associate editor for the Journal of Decision Systems and on the editorial board for the International Journal of Decision Support Systems Technology. She conducts regular review for 3 research councils and 10 international journals.

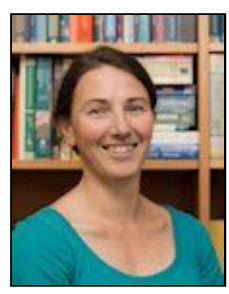

Melanie Hudson Smith is a lecturer in operations management at the University of Plymouth and is the leader of the operations and strategy subject group. Her primary research interests are operations analysis and improvement, sustainable supply chains and service quality, with recent publications and consultancy projects in these areas. She teaches operations and research methods at both undergraduate and postgraduate levels and supervises a number of $\mathrm{PhD}$ students. 